\title{
EFFECT OF HOT ISOSTATIC PRESSING ON THE MICROSTRUCTURE OF TURBINE BLADE AIRFOIL MADE OF NICKEL-BASE SUPERALLOY
}

\begin{abstract}
Turbine blades are flight safety parts in the jet engine. Therefore they should be characterized by very good mechanical properties, especially high creep resistance and fatigue strength at high temperature. The mechanical properties of blades made of nickel-based superalloys depend on the microstructure of the casting and its porosity $[1,2]$.

The aim of this paper is evaluation of effect of hot isostatic pressing (HIP) on microstructure of blade airfoil made of IN713C superalloy in four important zones: (i) leading edge, (ii) trailing edge, (iii) suction side and (iv) pressure side. HIP treatment was carried out proving some significant microstructural changes. Electron backscatter diffraction (EBSD) analysis reveals some structural changes what may facilitate diffusion processes leading to simplify of a heat treatment (solution treatment and aging).

Keywords: superalloys, turbine blades, HIP, EBSD
\end{abstract}

\section{Introduction}

The IN713C superalloy is widely used in aerospace industry due to low cost and good mechanical properties. Turbine blades made of the superalloys work at very high temperature, often exceeding $1200^{\circ} \mathrm{K}$ in the combustion chamber [1-3]. The necessary conditions of the high creep resistance and the fatigue strength of the blades at high temperature are the proper microstructure and very low internal porosity [1-4]. Hot isostatic pressing (HIP) is commonly used to decrease the porosity and healing the creep cavities [5-8]. Nickel-based superalloys are precipitation-strengthened materials with a high relative volume of the $\gamma^{\prime}$ phase $\left(\mathrm{Ni}_{3}(\mathrm{Al}, \mathrm{Ti})\right)$, and HIP is usually performed at a temperature slightly below the $\gamma^{\prime}$-solvus temperature [8].

The paper presents the effect of HIP treatment on the microstructure of the polycrystalline turbine blades made of IN713C superalloy.

\section{Experimental}

Two polycrystalline turbine blades (with equiaxed grains) were used in this study. The blades were made of the IN713C nickel-base superalloy. The chemical composition of IN713C is shown in Table 1.

One blade was characterized in the as-cast state, but the another blade was investigated after HIP treatment. For microstructural characterization, the samples were sectioned from the mid-airfoil area (Fig. 1).
TABLE 1

Chemical composition of IN713C superalloy (wt. \%)

\begin{tabular}{|c|c|c|c|c|c|c|c|c|}
\hline \hline Ni & $\mathbf{C r}$ & $\mathbf{M o}$ & $\mathbf{N b}$ & $\mathbf{A l}$ & $\mathbf{T i}$ & $\mathbf{C}$ & $\mathbf{B}$ & $\mathbf{Z r}$ \\
\hline Balance & 12.5 & 4.2 & 2 & 6 & 0.8 & 0.12 & 0.012 & 0.1 \\
\hline
\end{tabular}

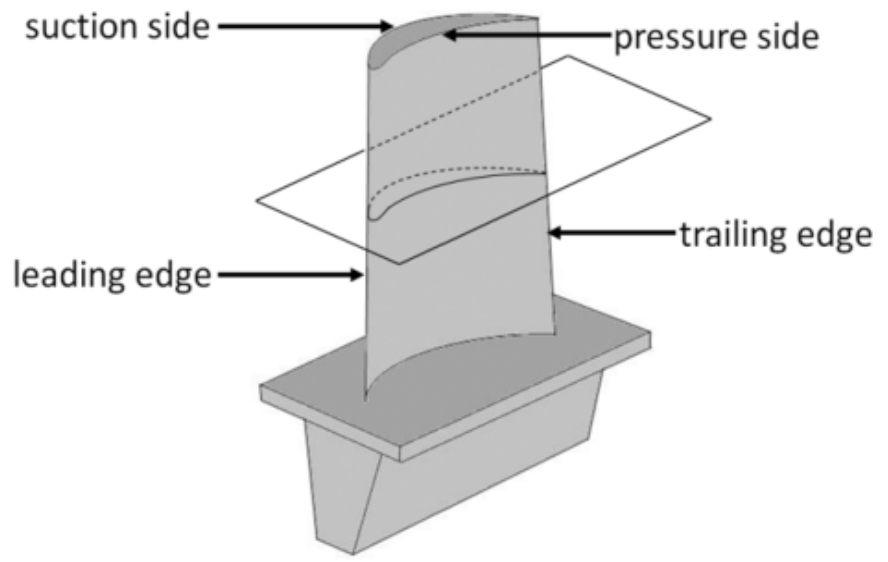

Fig. 1. Turbine blade with highlighted four characteristic zones

The samples were mechanically ground on abrasive paper (grit sizes: 320, 600, 800 and 1000) and polished on diamond suspensions (grit sizes: $9 \mu \mathrm{m}, 3 \mu \mathrm{m}, 1 \mu \mathrm{m}$ and $0.25 \mu \mathrm{m}$, respectively). The last stage of preparation was polishing using an alumina suspension (grit size: $0.05 \mu \mathrm{m}$ ). After ultrasonic cleaning, two different etchings were applied: (1) electrochemical etching in $10 \%$ oxalic acid solution (voltage: $6 \mathrm{~V}$, time: $5 \mathrm{~s}$ ) to

\footnotetext{
SILESIAN UNIVERSITY OF TECHNOLOGY, FACULTY OF MATERIALS ENGINEERING AND METALLURGY, INSTITUTE OF MATERIALS SCIENCE, 8 KRASINSKIEGO STR., 40-019 KATOWICE, POLAND

\# Corresponding author: bartosz.chmiela@polsl.pl
} 
dissolve the $\gamma$ matrix and reveal the $\gamma^{\prime}$ particles; (2) chemical etching in a solution of $100 \mathrm{~cm}^{3} \mathrm{HCl}, 100 \mathrm{~cm}^{3} \mathrm{HNO}_{3}, 100 \mathrm{~cm}^{3}$ $\mathrm{H}_{2} \mathrm{O}$ and $3 \mathrm{~g} \mathrm{MoO}_{3}$ to dissolve the $\gamma^{\prime}$ particles. Microstructural investigations were performed using Hitachi S-4200 and Hitachi S-3400N scanning electron microscopes (SEM), both equipped with energy dispersive X-ray spectrometers (EDS) (Thermo Noran). Moreover, electron backscatter diffraction (EBSD, INCA HKL Nordlys II with Channel 5 software) analysis in four characteristic zones (Fig. 2) of the blades were carried out with a step size of about $1 \mu \mathrm{m}$. For EBSD analysis, samples were additionally polished using an alumina suspension (grit size: $0.05 \mu \mathrm{m}$ ) for $5 \mathrm{~h}$ with vibration.

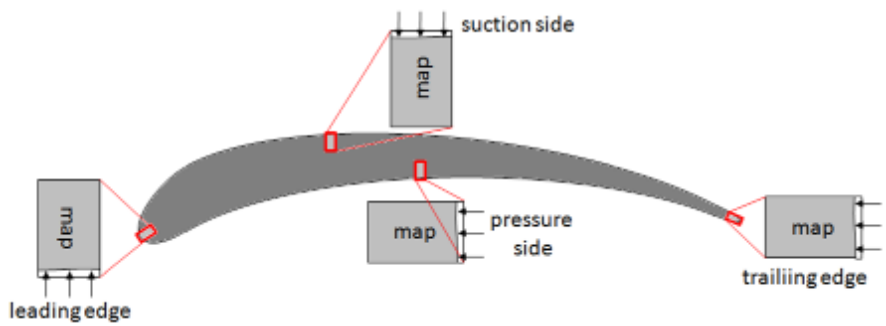

Fig. 2. Ares for EBSD investigation on the cross-section of turbine blade (arrows denote the surface layer of various blade areas)
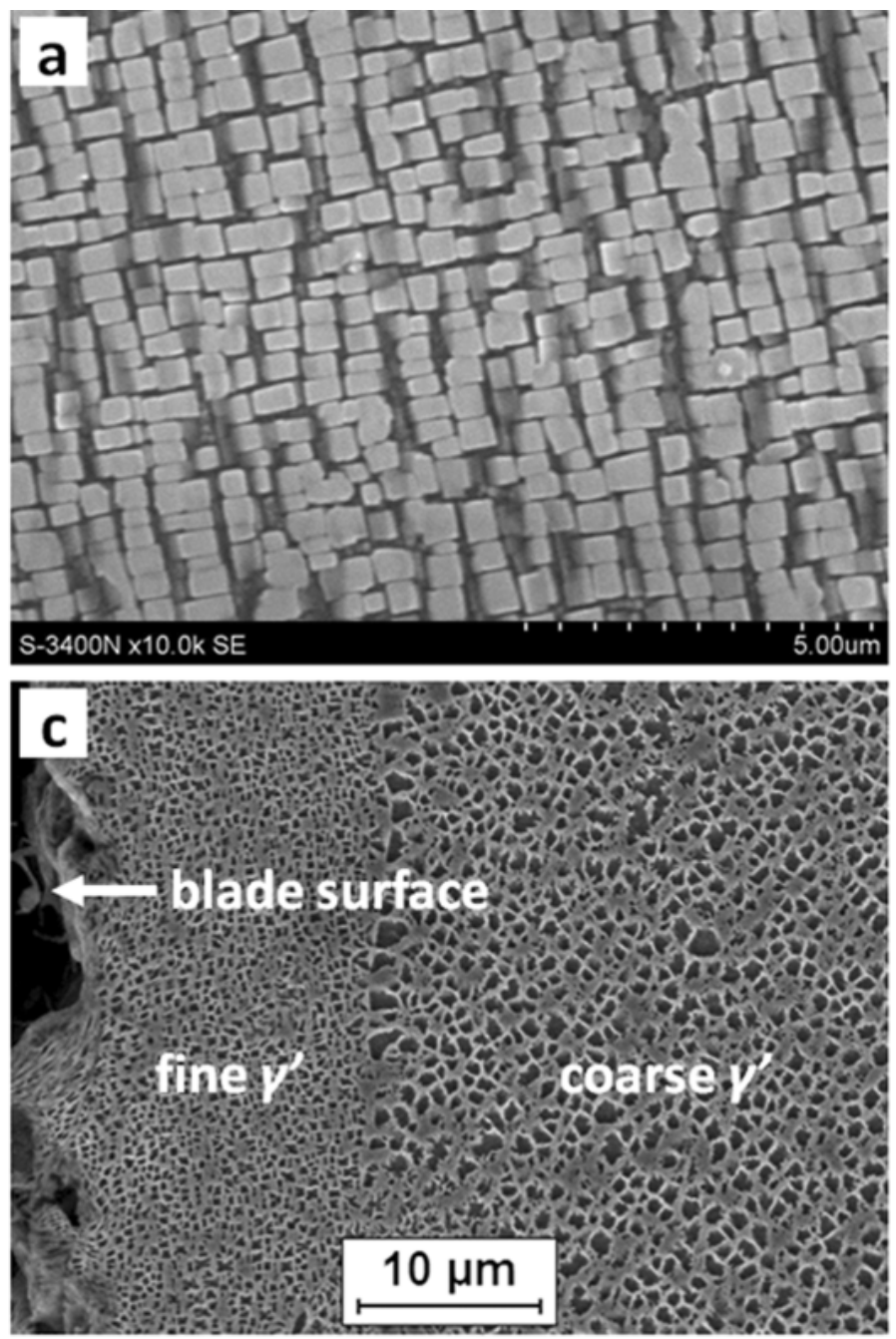

\section{Results and discussion}

The microstructure of IN713C superalloy in as-cast state consists of $\gamma^{\prime}\left(\mathrm{Ni}_{3}(\mathrm{Al}, \mathrm{Ti})\right)$ particles in $\gamma$ matrix, primary $\mathrm{MC}$ carbides and small amount of $\gamma / \gamma^{\prime}$ eutectics. The $\gamma^{\prime}$ particles are characterized by cubic shape within dendrites (Fig. 3a) and irregular shape in the interdendritic areas. The average edge length of $\gamma^{\prime}$ particle is about $0.5 \mu \mathrm{m}$. The revealed microstructure is characteristic for the whole volume of the blade airfoil.

However, HIP treatment leads to many microstructural changes in the blade. The characteristic feature is the change of the $\gamma^{\prime}$ morphology, from cubic to irregularly shaped, in dendrites (Fig. 3b).

Moreover, the characteristic refinement of the $\gamma^{\prime}$ particles in the surface layer (about $20 \mu \mathrm{m}$ of thickness) of the blade was observed (Fig. 3c). The average edge length of $\gamma^{\prime}$ particles in the surface layer was about $0.3 \mu \mathrm{m}$. The refinement of the $\gamma^{\prime}$ particles in the surface layer was likely caused by the combination of hydrostatic pressure and high temperature, modifying the thermodynamic equilibrium state, and the precipitation of the $\gamma^{\prime}$ particles from supersaturated solid solution during the cooling stage of HIP [8]. Moreover, it is known that the $\gamma^{\prime}$ particles can

Fig. 3. SEM images of turbine blade microstructure: (a) $\gamma^{\prime}$ particles in dendrite in as-cast state; (b) $\gamma^{\prime}$ particles in dendrite after HIP; (c) refinement

of $\gamma^{\prime}$ particles in the blade surface layer after HIP; (d) refinement of $\gamma^{\prime}$ particles in the vicinity of primary carbides after HIP
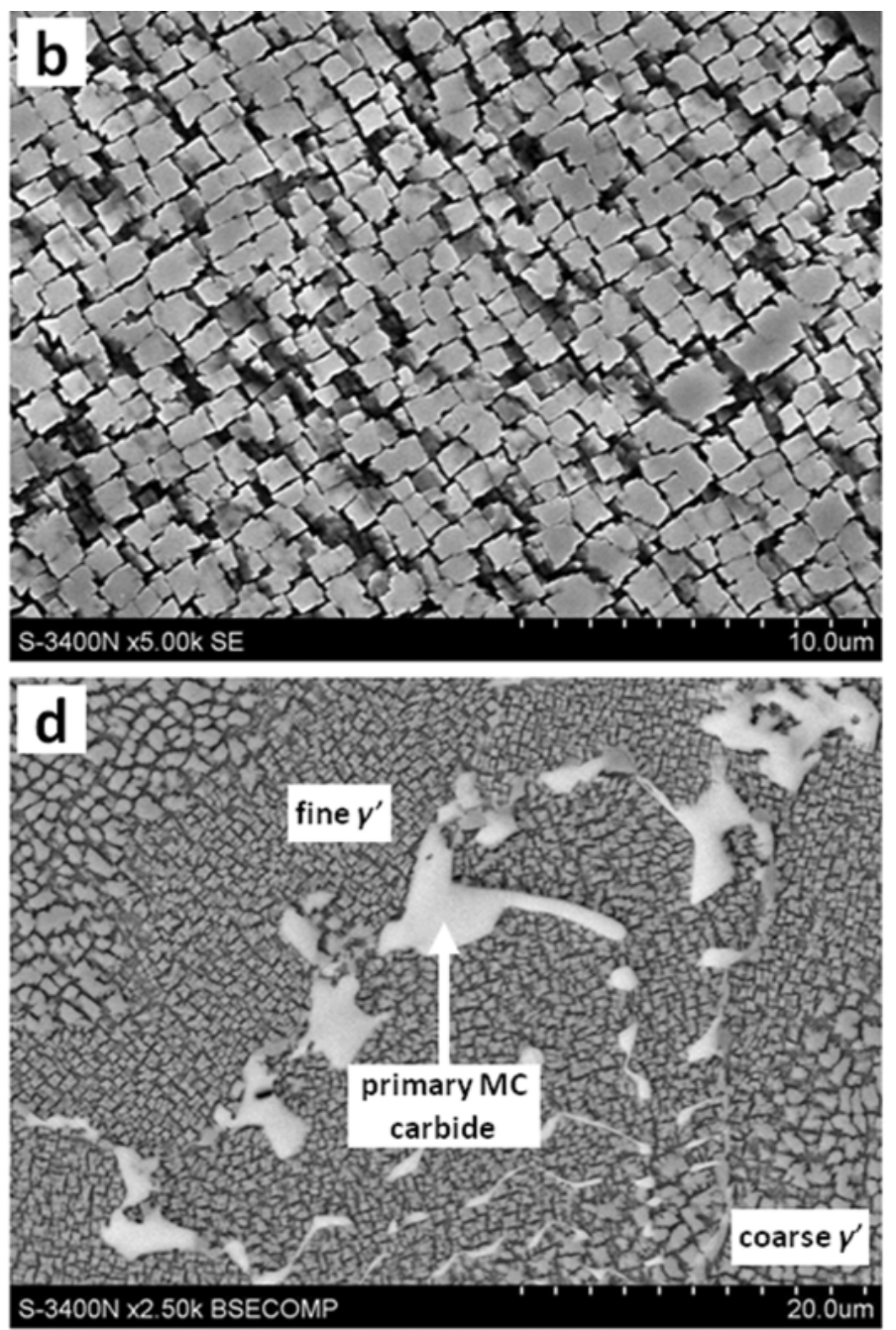
precipitate in the $\gamma$ matrix during gradual cooling below the $\gamma^{\prime}$ solvus temperature [9].

The refinement of the $\gamma^{\prime}$ particles in the vicinity of primary MC carbides was also observed (Fig. 4).

These refinements of the $\gamma^{\prime}$ phase suggest that a reaction between the $\gamma$ matrix and primary carbides, leading to new $\gamma^{\prime}$ particles, took place (1):

$$
\gamma+\mathrm{MC} \rightarrow \gamma^{\prime}+\mathrm{M}_{\mathrm{a}} \mathrm{C}_{\mathrm{b}}
$$

where: $\gamma$ is the matrix of Ni-base superalloy (solid solution of alloying elements in $\mathrm{Ni}$ ), $\mathrm{MC}$ is the primary carbide, $\gamma^{\prime}$ is the
$\mathrm{Ni}_{3}(\mathrm{Al}, \mathrm{Ti})$ phase and $\mathrm{M}_{\mathrm{a}} \mathrm{C}_{\mathrm{b}}$ is the secondary carbide ("a", "b" are stoichiometric coefficients).

The $\gamma$ matrix in IN713C superalloys is characterized by a high concentration of chromium. Therefore, during the reaction (1) at high temperatures, MC carbide is enriched with chromium, transforming it to secondary carbides, mainly $\mathrm{M}_{23} \mathrm{C}_{6}$. As a result, the $\gamma$ matrix is strongly depleted of chromium, leading to the creation of the new stable phase $\gamma^{\prime}\left(\mathrm{Ni}_{3}(\mathrm{Al}, \mathrm{Ti})\right)$. Although the primary carbides are in the interdendritic areas (where the $\gamma^{\prime}$ particles are irregularly shaped), the new, finer $\gamma^{\prime}$ particles are characterized by their cubic shape.
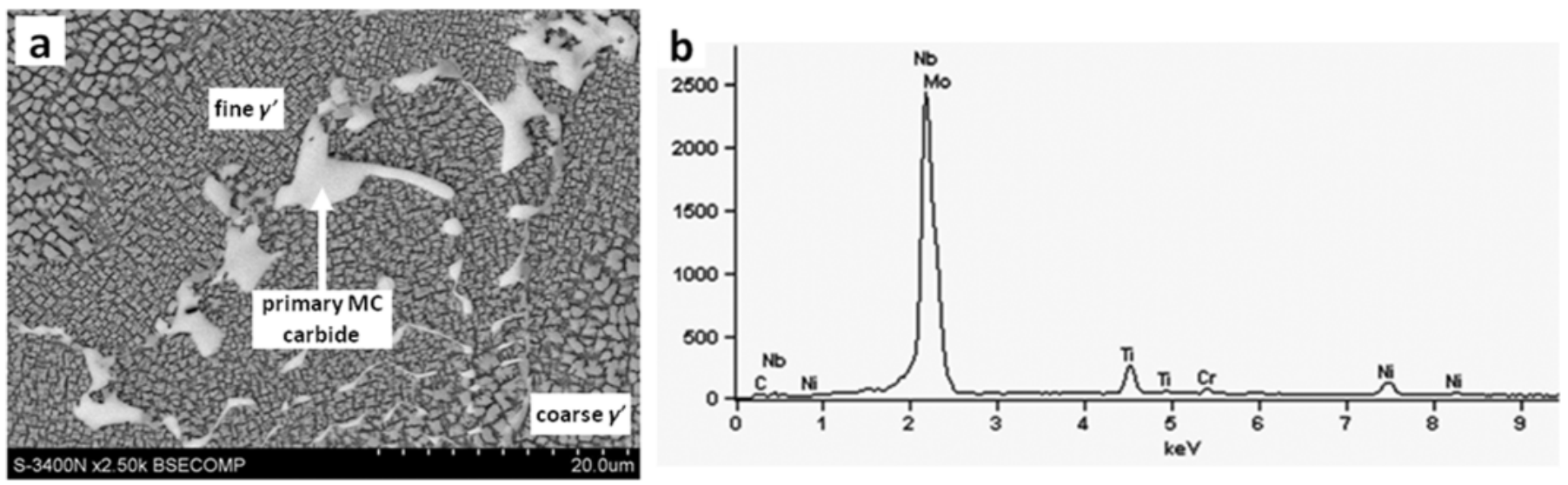

Fig. 4. Refinement of the $\gamma^{\prime}$ particles in the vicinity of the primary MC carbides after HIP (a); EDS spectrum of the carbide (b) in the blade made of IN713C superalloy

EBSD investigations deliver some important results. To estimate the extent of deformation (strain) after HIP treatment, EBSD analysis on the basis of orientation maps (with Inverse Pole Figures (IPF) colour scheme) and strain contouring maps (SC) was performed. The strain contouring map (qualitative only) was formed by measurement the maximum misorientation between any two points in a grain and weighted the grain according to the misorientation value. The orientation map of the suction side of the blade airfoil in as-cast state is shown in
(Fig. 5a). High angle grain boundaries (HABs) with misorientations higher than $15^{\circ}$ are presented as thick black lines and low angle boundaries (LABs) are highlighted as thin black lines. A very small amount of LABs are visible very close to the blade surface (Fig. 5a). (Fig. 5b) shows the strain contouring map from the same area. There are few weakly deformed areas - strain likely remained after solidification.

Orientation maps for blades after HIP treatment are presented in (Fig. 6). Grain refinement was observed in the surface
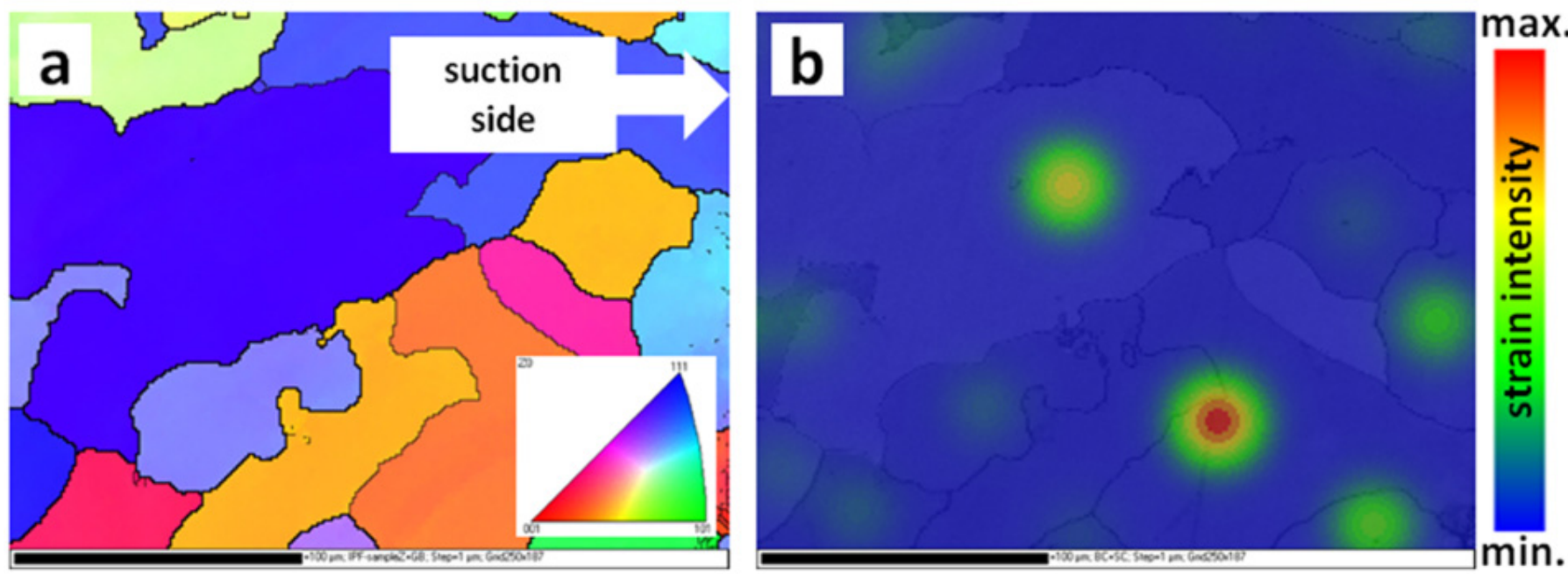

Fig. 5. Orientation map (a) with grain boundaries (Inverse Pole Figures colour scheme) and strain contouring map (b) of the suction side of the turbine blade (as-cast state) 

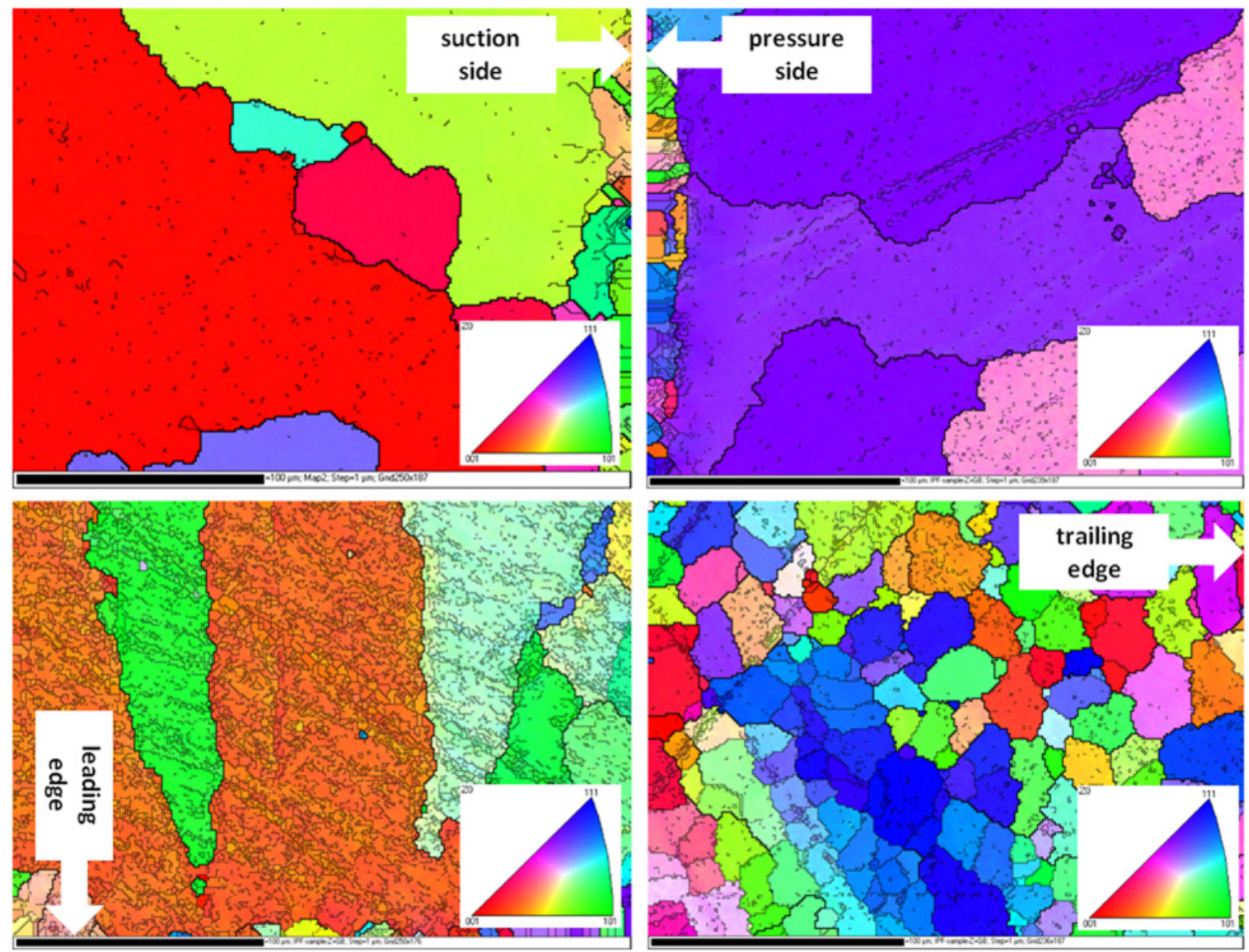

Fig. 6. Orientation maps with grain boundaries (Inverse Pole Figures colour scheme) for the blade airfoil after HIP treatment
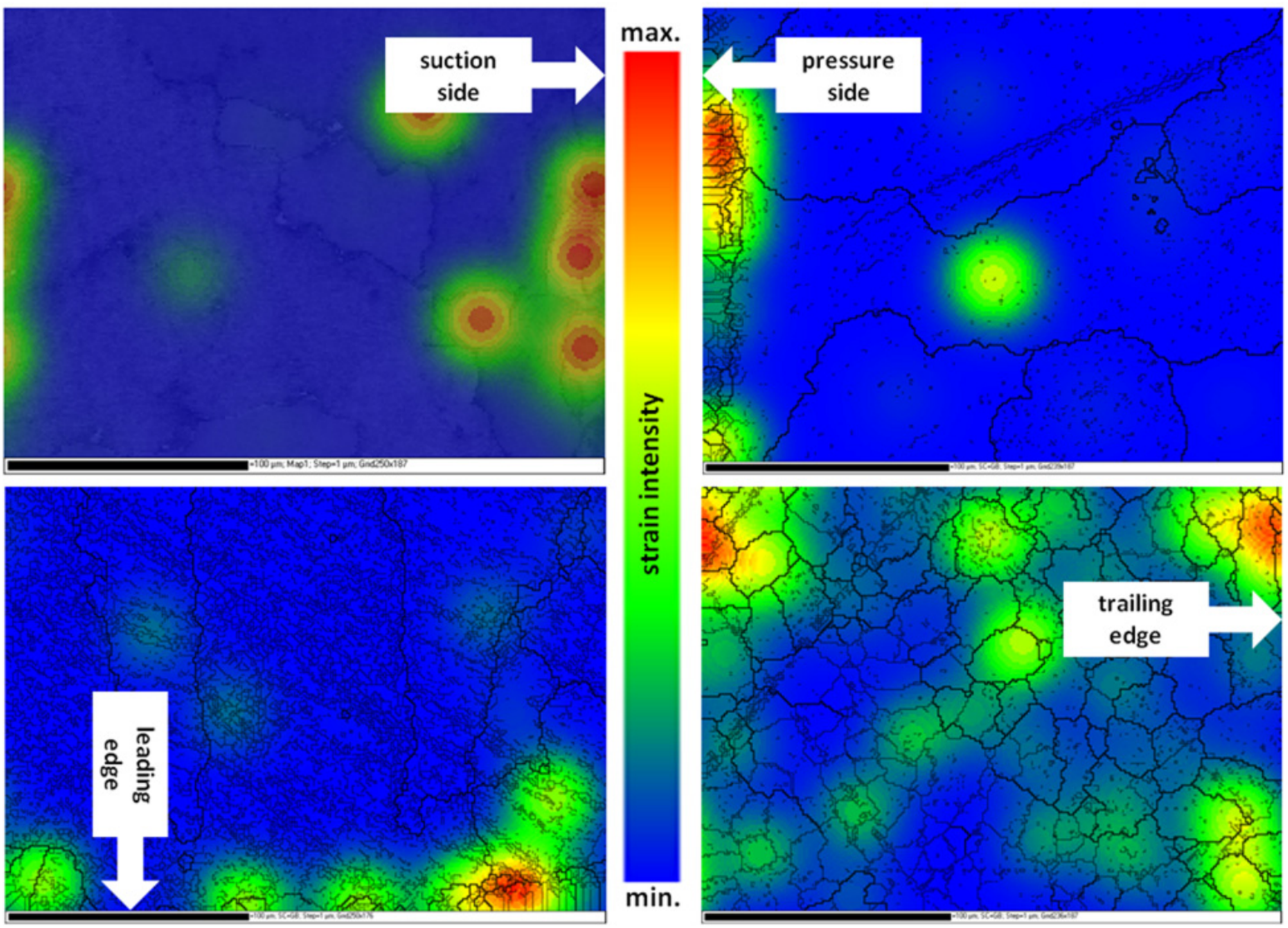

Fig. 7. Strain contouring maps with grain boundaries for the blade airfoil after HIP treatment 
layer of the suction side, the pressure side and the leading edge. The whole trailing edge was characterized by strong grain refinement (Fig. 6), because the curvature radius of this edge was very small what caused fast solidification during casting and the highest strain during HIP. In contrast to the as-cast blade, many LABs formed due to the high pressure during HIP. In case of the suction side and the pressure side (with large curvature radius), typical LABs forming the subgrains were present very close to the blade surface; but about $20 \mu \mathrm{m}$ below the surface there were only some short segments of LABs, separating of very small areas inside grains with misorientation lower than $15^{\circ}$ (Fig. 6). However, in case of the leading edge and the trailing edge, LABs formed subgrains in the whole area of interest (Fig. 6).

Strain contouring maps for the blade after the HIP treatment are presented in (Fig. 7). Strain contouring maps revealed that the most strained areas are close to the surface of the blade and sometimes deeper in the blade. The highest strain intensity is about $20 \mu \mathrm{m}$ from the blade surface. It is important that the areas with the highest strain intensity are not continuous - they do not form continuous zones along the surface layer. This is related to the variation in Young's moduli in various grains depending on their crystallographic orientation [10]. For nickel-based superalloys, the highest value of Young's modulus is along the $<111>$ direction, followed by the $\langle 110\rangle$ direction and the lowest is in the $<001>$ direction [10]. Thus, the highest strain intensity was detected in the grains with $<001>$ or $<101>$ directions perpendicular to the surface of the blades.

\section{Conclusions}

HIP treatment caused many microstructural changes: (i) the morphology of $\gamma^{\prime}$ particles changed from cubic to irregular in the dendrites; (ii) refinement of the $\gamma^{\prime}$ particles in the surface layer and in the vicinity of primary MC carbides was observed; (iii) EBSD analysis revealed high strain intensity in the surface layer of the blades - the most strained are grains in which the $\{101\}$ and $\{100\}$ directions are perpendicular to the cross-section of the blade. Surface layer of the blade airfoil is characterized by high amount of low angle boundaries (LABs), what can facilitate the diffusion processes thus leading to simplify the heat treatment of the blades.

\section{Acknowledgements}

A financial support by the Polish National Centre for Research and Development involved in the carrying-out of Project No. INNOLOT/I/8/NCBR/2013 entitled Innovative investment casting technologies - INNOCAST" is gratefully acknowledged.

\section{REFERENCES}

[1] R.C. Reed, Superalloys: Fundamentals and applications, Cambridge University Press, 2006.

[2] M. Durand-Charre, The microstructure of superalloys, Gordon and Breach Science Publishers, 1997.

[3] M.J. Donachie, S.J. Donachie, Superalloys: A technical guide, ASM International.

[4] Yu Kuang-O (Oscar) et. al., Modelling for casting and solidification processing, Marcel Dekker Inc. 2002.

[5] L. Kunz, P. Lukáš, R. Konečná, S. Fintová, Int. J. Fatigue 41, 47-51 (2012).

[6] S.H. Chang, J. Alloys and Compounds 486, 716-721 (2009).

[7] K.O. Lee, S.B. Lee, Mat. Sci. Eng. A 541, 81-87 (2012).

[8] Y. Zhou, S. Rao, Z. Zhang, Z. Zhao, Mat. and Design 49, 25-27 (2013).

[9] S. Zlá, B. Smetana, M. Žaludová, J. Dobrovská, V. Vodárek, K. Konečná, V. Matějká, H. Francová, J. Thermal Anal. and Cal. 110, 211-219 (2012).

[10] H. Takagi, M. Fujiwara, K. Kakehi, Mat. Sci. Eng. A 387, 348-351 (2004). 